\title{
ANALISIS KEBIASAAN MEROKOK TERHADAP KEJADIAN TUBERKULOSIS PARU DI WILAYAH KERJA PUSKESMAS PATUMBAK
}

\author{
Novrika Silalahi, Santy Fransiska \\ Institut Kesehatan Deli Husada Delitua, Jalan Besar No. 77 Delitua \\ e-mail: novrikasilalahi29@gmail.com
}

\begin{abstract}
Tuberculosis and smoking is a major problem that have an impact to health problem in the world. Indonesia is one of the country with highest incidence of tuberculosis in the world, and one of the biggest three country that high in smoker consumers. Smoking is not the only one connected with health problem because of uninfected disease, but with higher risk of sickness and death cause of infected diseases, like tuberculosis patients in 2016 is 107 people and smoker with 571 people. Purpose of the reseach is to achieve the connection between smoking habituation with a lot of numbers patients tuberculosis in Health Center Patumbak year of 2017. Usingresearch analitic with case control. Thepopulation in this research come from the patients that seek medication in Health Center Patumbak as much as 89 people. The Purposive of the sampling is used in sampling technique. Gathering the data use interviews with questionnaire. The analysis result showing that majority of smoker $43,8 \%$. The patient with tuberculosis is $80,9 \%$. There's connection between smoking habituation with tuberculosis.
\end{abstract}

Keywords: smoking habituation, tuberculosis

\section{PENDAhuluan}

Penyakit TBC (Tuberkulosis) salah satu penyakit kronis (menahun) telah lama dikenal masyarakat luas dan ditakuti, karena menular. Namun demikan TBC dapat disembuhkan dengan memakan obat anti TB dengan betul yaitu teratur sesuai petunjuk dokter atau petugas kesehatan lainnya (Misnadiarly, 2011).

Berdasarkan data World Health Organization (WHO) pada tahun 2014 diperkirakan 8,7 juta orang di dunia menderita $T B$, setara dengan 125 kasus per 100.000 populasi. Penelitian oleh WHO menyatakan bahwa estimasi angka kematian karena TB dunia pada pasien HIV negatif dan positif berkisar 20 kematian per 100.000 populasi. Penyebaran terbanyak penyakit TB adalah di kawasan Asia (59\%) dan dilanjutkan Afrika (26\%). Sejumlah kecil kasus terjadi di daerah Mediterania (7,7\%),
Eropa (4,3\%), dan Amerika (3\%) (Manalu, 2014).

Pada tahun 2014 ditemukan jumlah kasus baru BTA+ sebanyak 176.677 kasus, menurun bila dibandingkan kasus baru BTA+ yang ditemukan tahun 2013 yang sebesar 196.310 kasus. Jumlah kasus tertinggi yang dilaporkan terdapat di provinsi dengan jumlah penduduk yang besar yaitu Jawa Barat, Jawa Timur, dan Jawa Tengah.Kasus baru BTA+ di tiga provinsi tersebut sebesar $40 \%$ dari jumlah seluruh kasus baru di Indonesia. Menurut jenis kelamin, kasus BTA+ pada laki-laki lebih tinggi daripada perempuan yaitu 1,5 kali dibandingkan kasus BTA+ pada perempuan. Pada masing-masing provinsi di seluruh Indonesia kasus BTA+ lebih banyak terjadi pada laki-laki dibandingkan perempuan.

Disparitas paling tinggi antara laki-laki dan perempuan terjadi di Kepulauan Bangka Belitung, kasus pada laki-laki hampir dua kali 


\begin{tabular}{c|c|c}
\hline JURNAL PENELITIAN KESMASY & VOL. 1 NO. 2 & $\begin{array}{c}\text { EDITION: NOVEMBER 2018 - } \\
\text { APRIL 2019 }\end{array}$ \\
\hline & http://ejournal.delihusada.ac.id/index.php/JPKSY & \\
\cline { 2 - 3 } RECEIVED: 17 FEBRUARI 2019 & REVISED: 18 MARET 2019 & ACCEPTED: 28 APRIL 2019 \\
\hline
\end{tabular}

lipat dari kasus pada perempuan. Menurut kelompok umur, kasus baru paling banyak ditemukan pada kelompok umur 25-34 tahun yaitu sebesar $20,76 \%$ diikuti kelompok umur 45-54 tahun sebesar $19,57 \%$ dan pada kelompok umur 35-44 tahun sebesar 19,24\% (Kemenkes RI, 2014).

Menurut hasil Riskesdas 2013, prevalensi TB berdasarkan diagnosis sebesar $0,4 \%$ dari jumlah penduduk. Menurut provinsi, prevalensi TB paru tertinggi berdasarkan diagnosis yaitu Jawa Barat sebesar 0,7\%, DKI Jakarta dan Papua masing-masing sebesar 0,6\%. Sedangkan Provinsi Riau, Lampung, dan Bali merupakan provinsi dengan prevalensi TB paru terendah berdasarkan diagnosis yaitu masing-masing sebesar $0,1 \%$. Sedangkan menurut Global Tuberculosis Control, estimasi insidens semua tipe TB tahun 2013 yang sebesar 183 per 100.000 penduduk mengalami penurunan dibandingkan tahun 1990 yang sebesar 343 per 100.000 penduduk. Begitu juga dengan prevalensi TB dan mortalitas yang mengalami penurunan pada tahun 2013 (Kemenkes RI, 2014)

Berdasarkan jumlah penduduk tahun 2013, diperhitungkan sasaran penemuan kasus baru TB Paru BTA (+) di Provinsi Sumatera Utara adalah sebesar 21.322 jiwa, dan hasil cakupan penemuan kasus baru TB Paru BTA (+) yaitu 15.414 kasus atau $72,29 \%$. Angka ini mengalami penurunan bila dibandingkan dengan tahun 2012 sebesar 82,57\% dan tahun 2011 sebesar 76,57\%. Berdasarkan jumlah penduduk tahun 2013, diperhitungkan sasaran penemuan kasus baru TB Paru BTA (+) di Provinsi Sumatera Utara adalah sebesar 21.322 jiwa, dan hasil cakupan penemuan kasus baru TB Paru BTA (+) yaitu 15.414 kasus atau $72,29 \%$.

Angka ini mengalami penurunan bila dibandingkan dengan tahun 2012 sebesar 82,57\% dan tahun 2011 sebesar 76,57\%. Berdasarkan Profil Kesehatan Kabupaten/Kota tahun 2013, angka keberhasilan (Success Rate) rata-rata ditingkat provinsi mencapai $88,24 \%$, dengan perincian persentase kesembuhan $82,59 \%$ dan persentase pengobatan lengkap 5,66\%. Angka succes rate pada tahun 2013 ini telah mampu melampaui target nasional yaitu $85 \%$. Dari 33 $\mathrm{Kab} / \mathrm{Kota}$, terdapat $11 \mathrm{Kab} /$ Kota yang belum mampu mencapai angka success rate $85 \%$. Pada tahun 2013, Sumatera Utara belum mampu mencapai target nasional yaitu $75 \%$. Dari 33 kabupaten/kota yang ada di Provinsi Sumatera Utara, ditemukan 29 kabupaten/ kota memiliki angka penemuan kasus (CNR) TB Paru BTA (+) di atas $75 \%$. Angka CNR tertinggi di Kota Pematang Siantar sebesar 226,59\% dan terendah di Kabupaten Nias Barat sebesar 22,93\% (Profil Kesehatan Sumatera Utara, 2013).

Peningkatan jumlah kasus TB Paru di Indonesia didukung oleh kenaikan faktor risiko yaitu umur harapan hidup, kebiasaan merokok dan polusi udara. Merokok menjadi salah satu kebiasaan yang lazim dilakukan dalam kehidupan sehari-hari, sehingga dimanapun tempat selalu ditemukan orang merokok baik laki-laki, perempuan, anak kecil, anak muda, orang tua, status kaya atau miskin tanpa terkecuali. Padahal sebagian besar masyarakat sudah mengetahui bahaya dari merokok namun pada kenyataannya merokok telah menjadi kebudayaan. Rokok sangat berbahaya bagi kesehatan karena rokok memilki dampak fisiologis (kerontokan pada rambut, gangguan pada mata, infeksi pada telinga, gangguan sistem pernapasan, merusak gigi, merusak kekuatan tulang, mengganggu fungsi jantung dan pembuluh darah) dan psikologis (ketagihan, toleransi dan dependensi) bagi manusia. Kebiasaan merokok tidak hanya dikaitkan dengan masalah kesehatan akibat penyakit tidak menular, tetapi juga dengan peningkatan risiko kesakitan dan kematian akibat penyakit menular, seperti tuberkulosis (Tarwoto, 2010).

Tahun 2012 persentase prevalensi perokok pria yaitu $67 \%$ jauh lebih besar daripada perokok wanita yaitu $2,7 \%$. Diantara para perokok tersebut terdapat $56,7 \%$ pria dan $1,8 \%$ wanita merokok setiap hari. Terdapat 


\begin{tabular}{c|c|c}
\hline JURNAL PENELITIAN KESMASY & VOL. 1 NO. 2 & $\begin{array}{c}\text { EDITION: NOVEMBER 2018 - } \\
\text { APRIL 2019 }\end{array}$ \\
\hline \multirow{2}{*}{ RECEIVED: 17 FEBRUARI 2019} & http://ejournal.delihusada.ac.id/index.php/JPKSY & \\
\cline { 2 - 2 } & REVISED: 18 MARET 2019 & ACCEPTED: 28 APRIL 2019 \\
\hline
\end{tabular}

beberapa negara yang tergolong paling tinggi tingkat perokoknya yaitu China 390 juta perokok atau 29\% penduduk, India 144 juta perokok atau $12.5 \%$ penduduk, Indonesia 65 juta perokok atau $28 \%$ penduduk (225 miliar batang tahun), Rusia 61 juta perokok atau 43\% penduduk, Amerika Serikat 58 juta perokok atau $19 \%$ penduduk, Jepang 49 juta perokok atau 38\% penduduk, Brazil 24 juta perokok atau $12.5 \%$ penduduk, Bangladesh 23.3 juta perokok atau $23.5 \%$ penduduk, Jerman 22.3 juta perokok atau $27 \%$, Turki 21.5 juta perokok atau $30.5 \%$.

Penelitian Sarwani (2012) didapatkan hasil ada hubungan yang signifikan antara merokok dengan kejadian Tuberkulosis paru $(p=0,022$, $\mathrm{OR}=3,85 ; 95 \% \mathrm{CI}=1,32$ - 11,23). Penelitian Falletehan (2014) bahwa terdapat hubungan perilaku merokok dengan kejadian TB paru dengan nilai $p=0,027$. Begitu juga dengan Penelitian Soetioso (2014) yaitu ada hubungan antara kebiasaan merokok dengan derajat kepositivan sputum BTA $(p=0,010)$. Sejalan juga dengan penelitian Priyadi yaitu adanya hubungan yang bermakna antara kebiasaan merokok dengan kejadian TB paru.

Hasil survey awal yang dilakukan di wilayah kerja Puskesmas Patumbak penderita tuberkulosis paru pada tahun 2015 sebanyak 180, tahun 2016 sebanyak 107 orang, meskipun data penderita tuberkulosis paru mengalami penurunan namun perokok semakin meningkat yaitu pada tahun 2015 terdapat 434 orang dan pada tahun 2016 sebanyak 571 orang. Aktivitas merokok sudah dilakukan pada usia remaja, biasanya dimulai setelah pulang sekolah dan dilakukan di luar lingkungan sekolah. Berdasarkan latar belakang diatas maka peneliti tertarik untuk melakukan penelitian tentang hubungan kebiasaan merokok dengan kejadian tuberkulosis paru di wilayah kerja Puskesmas Patumbak.

Berdasarkan uraian di atas, maka yang menjadi rumusan masalah pada penelitian ini adalah apakah ada hubungan kebiasaan merokok dengan kejadian tuberkulosis paru di wilayah kerja Puskesmas Patumbak dengan menggunakan analisis data chi-square.

\section{METODE PENELITIAN}

Jenis penelitian ini adalah penelitian kuantitatif yang bersifat survei analitik dengan desain penelitian cross sectional. Populasi dalam penelitian ini adalah seluruh pasien yang berobat di Puskesmas Patumbak sebanyak 89 orang dengan teknik pengambilan sampel yang digunakan adalah purposive sampling.

\section{HASIL DAN PEMBAHASAAN}

\section{Kebiasaan Merokok Masyarakat}

Tabel 1. Responden Berdasarkan Kategori Kebiasaan Merokok Masyarakat

\begin{tabular}{clcc}
\hline No & \multicolumn{1}{c}{ Kategori } & (f) & (\%) \\
\hline 1 & Perokok sangat berat & 21 & 23,6 \\
2 & Perokok berat & 39 & 43,8 \\
3 & Perokok sedang & 25 & 28,1 \\
4 & Perokok ringan & 4 & 4,5 \\
\hline & Total & $\mathbf{8 9}$ & $\mathbf{1 0 0}$ \\
\hline
\end{tabular}

Tabel di atas menunjukkan bahwa masyarakat yang menjadi perokok sangat berat sebanyak 21 orang $(23,2 \%)$, perokok berat sebanyak 39 orang $(43,8 \%)$, perokok sedang sebanyak 25 orang $(28,1 \%)$ dan perokok ringan sebanyak 4 orang $(4,5 \%)$.

Menurut asumsi peneliti kebiasaan merokok dianggap dapat memberikan kenikmatan bagi perokok, namun di lain pihak dapat menimbulkan dampak buruk baik perokok sendiri maupun orang-orang di sekitarnya. Berbagai kandungan zat yang terdapat di dalam rokok memberikan dampak negatif bagi tubuh penghisapnya.

Pada umumnya responden, melakukan kebiasaan merokok awalnya dari coba-coba dan diajak teman. Ketika mereka mulai menikmati dan merasakan enak, maka mereka akan terus melanjutkan perilaku merokok tersebut. Disisi lain, ketika mereka mendapati bahwa kebiasaan merokok yang mereka lakukan tidak ditentang oleh masyarakat sekitarnya karena faktor kebiasaan, maka mereka merasa bahwa perilaku merokok 


\begin{tabular}{c|c|c}
\hline JURNAL PENELITIAN KESMASY & VOL. 1 NO. 2 & $\begin{array}{c}\text { EDITION: NOVEMBER 2018 - } \\
\text { APRIL 2019 }\end{array}$ \\
\hline & http://ejournal.delihusada.ac.id/index.php/JPKSY & \\
\cline { 2 - 3 } RECEIVED: 17 FEBRUARI 2019 & REVISED: 18 MARET 2019 & ACCEPTED: 28 APRIL 2019 \\
\hline
\end{tabular}

adalah hal yang boleh mereka lakukan. Hal tersebut sebagaimana dikemukakan oleh Bandura (yang dikutip dalam Fadila, 2010) yang menyatakan bahwa kebiasaan merokok dapat terjadi secara biologis yang merupakan naluri pembawaan dan dapat dipelajari melalui observasi dan peniruan.

Perilaku merokok dapat dipelajari melakui observasi dan peniruan (imitasi), semakin sering mendapatkan penguatan semakin besar terjadinya perilaku merokok. Orang yang frustasi karena tujuannya terhambat oleh peristiwa yang menimbulkan stress, akan mengalami keterbangkitan emosional yang tidak menyenangkan. Pengalaman tidak menyenangkan menimbulkan gangguan emosi yang cenderung meningkatkan perilaku merokok. Perilaku merokok pada remaja mudah sekali ditularkan kepada temannya, salah satunya teman ditempat kerja.

Hal tersebut sebagaimana pendapat Mu'tadin (2012), yang menyatakan bahwa salah satu faktor yang sangat kuat mempengaruhi perilaku merokok dewasa awal adalah pengaruh teman. Perilaku dewasa awal dipengaruhi oleh lingkungan tempat mereka bergaul, mereka mempunyai hasrat mengikuti kelompok untuk sama dengannya dan ingin mencoba sesuatu yang dianggap menyenangkan. Menurut Komalasari \& Helmi (2010), alasan mengapa seseorang merokok salah satunya karena faktor individu. Orang mencoba untuk merokok karena alasan ingin tahu atau ingin melepaskan diri dari rasa sakit dan kebosanan.

Tabel 2 Responden Berdasarkan Kejadian Tuberkulosis Paru

\begin{tabular}{llcc}
\hline No & \multicolumn{1}{c}{ Kategori } & $\begin{array}{c}\text { Freku } \\
\text { ensi } \\
\text { (f) }\end{array}$ & $\begin{array}{c}\text { Persent } \\
\text { ase } \\
(\%)\end{array}$ \\
\hline 1 & $\begin{array}{l}\text { Terjadi TB Paru } \\
2\end{array}$ & 72 & 80,9 \\
& $\begin{array}{l}\text { Tidak terjadi TB } \\
\text { Paru }\end{array}$ & 17 & 19,1 \\
\hline & Total & $\mathbf{8 9}$ & $\mathbf{1 0 0}$ \\
\hline
\end{tabular}

Tabel di atas menunjukkan bahwa masyarakat yang menderita TB paru sebanyak 72 orang $(80,9 \%)$ danmasyarakat yang tidak menderita
TB paru sebanyak 17 orang (19,1\%). Menurut asumsi peneliti adalah $\mathrm{Tb}$ penyakit menular langsung yang disebabkan oleh kuman TB (Mycobacteria Tuberkulosis). Masa inkubasinya yaitu waktu yang diperlukan mulai terinfeksi sampai terjadinya sakit, diperkirakan selama 4 sampai 6 minggu. Kuman ditularkan oleh penderita TB paru BTA positif melalui batuk, bersin atau saat berbicara lewat percikan droplet yang keluar. Seseorang dinyatakan menderita TB paru apabila sudah melakukan pemeriksaan dahak secara mikroskopis sebanyak 3 kali pemeriksaan (SPS) di laboratorium (Kemenkes, 2013).

Tuberkulosis paru yang muncul biasanya setelah terjadi infeksi ulang (reinfection) atau yang lebih dikenal dengan tuberkulosis paru post-primer. Sebagian besar tuberkulosis paru post primer terjadi karena adanya infeksi ulang yang berasal dari luar, meskipun ada juga yang berasal dari fokus lama tuberkulosis paru primer (dormant) yang kambuh (Alsagaff, 2010). Berbagai data epidemiologi telah menunjukkan bahwa merokok merupakan faktor risiko untuk terjadinya infeksi tuberkulosis paru. Kebiasaan merokok merupakan risiko untuk terinfeksi Mycobacterium tuberkulosis, selanjutnya infeksi akan berkembang menjadi penyakit dan berisiko kematian. Hampir $60 \%$ kematian penderita tuberkulosis berkaitan dengan kebiasaan merokok (WHO, 2010).

Perokok cenderung mengalami batuk kronik yang merupakan tanda penyakit tuberkulosis paru. Merokok juga menyebabkan gangguan secara bersamaan yaitu bronkitis kronis, obstruksi jalan napas kronis dan emfisema paru. Disamping penyakit tuberkulosis paru itu sendiri juga merusak fungsi paru (WHO, 2010). Merokok meningkatkan prevalensi kejadian tuberkulosis paru (Gupta et al., 2010). Kebiasaan merokok yang sudah dimulai sejak usia 15 tahun, memberikan hubungan antara merokok dengan tingginya angka tuberkulosis paru pada laki-laki (Kolappan \& Gopi, 2012). 


\begin{tabular}{c|c|c}
\hline JURNAL PENELITIAN KESMASY & VOL. 1 NO. 2 & $\begin{array}{c}\text { EDITION: NOVEMBER 2018 - } \\
\text { APRIL 2019 }\end{array}$ \\
\hline \multirow{2}{*}{ RECEIVED: 17 FEBRUARI 2019} & http://ejournal.delihusada.ac.id/index.php/JPKSY & ACCEPTED: 28 APRIL 2019 \\
\cline { 2 - 3 } & REVISED: 18 MARET 2019 & ACE \\
\hline
\end{tabular}

Menurut Gupta (2011) merokok dan tuberkulosis paru dapat saling mempengaruhi, karena baik asap rokok maupun kuman Mycobacterium tuberculosis dapat masuk melalui saluran pernapasan, meskipun merokok tidak berperan dalam etiologi tuberkulosis namun tingginya angka kejadian tuberkulosis dapat ditemukan pada perokok. Dari observasi yang dilakukan, angka kejadian tuberkulosis paru meningkat dengan meningkatnya jumlah rokok yang dihisap. Sedangkan merurut Susaniwati (2011) merokok mempengaruhi fungsi dan bentuk sel-sel inflamasi, antara lain makrofag alveolar pada perokok lebih besar dan mempunyai morfologi permukaan abnormal, adanya inklusi sitoplasmatik, sehingga mengakibatkan terganggunya presentasi antigen.

Interaksi langsung komponen toksik asap rokok dengan epitel setelah melewati pelapis antioksidan protektif pada cairan pelapis epitel (CPE) mengakibatkan kerusakan sel akibat bahan reaktif toksik yang dihasilkan dari interaksi antara asap rokok dengan CPE. Sehingga mengaktifkan respon imun dan selanjutnya terjadi respon inflamasi.

Menurut Muhammad (2011), seperti yang dikutip dari Brasher (1978), asap rokok dapat mengganggu aktivitas bulu getar saluran pernapasan. Partikel yang terdapat dalam asap rokok dan udara yang terpolusi mempunyai dampak yang besar terhadap pembersihan oleh system mukosilier. Sebagian partikulat tersebut mengendap pada lapisan mucus yang melapisi mukosa bronkus, sehingga menghambat aktivitas silia, pergerakan cairan yang melapisi mukosa bronkus akan sangat berkurang mengakibatkan meningkatnya iritasi pada epitel mukosa bronkus.

\section{Hubungan Kebiasaan Merokok Dengan Kejadian Tuberkulosis Paru Di Wilayah Kerja Puskesmas Patumbak}

Hasil analisis (tabel 3) kebiasaan merokok dengan kejadian TB paru diperoleh bahwa sebanyak $23,6 \%$ responden perokok sangat berat dengan menderita TB paru, sebanyak $43,8 \%$ responden perokok berat dengan menderita TB paru, sebanyak 14,6\% responden perokok sedang dengan tidak menderita TB paru, sebanyak 4,5\% perokok ringan dengan tidak menderita TB paru. Hasil uji statistik chi-square diperoleh nilai $\mathrm{p}=$ 0,021 maka dapat disimpulkan bahwa ada hubungan kebiasaan merokok dengan kejadian TB paru.

Tabel 3. Uji Chi-Square Kebiasaan Merokok Dengan Kejadian Tuberkulosis Paru

\begin{tabular}{|c|c|c|c|c|c|c|c|}
\hline \multirow{3}{*}{ Kebiasaan Merokok } & \multicolumn{4}{|c|}{ Kejadian Tuberkulosis Paru } & \multirow{2}{*}{\multicolumn{2}{|c|}{ Total }} & \multirow{3}{*}{ p-value } \\
\hline & \multicolumn{2}{|c|}{ Terjadi } & \multicolumn{2}{|c|}{ Tidak Terjadi } & & & \\
\hline & $\mathbf{F}$ & $\%$ & $\mathbf{F}$ & $\%$ & $\mathbf{F}$ & $\%$ & \\
\hline $\begin{array}{l}\text { Perokok sangat } \\
\text { berat }\end{array}$ & 21 & 23,6 & 0 & 0,0 & 21 & 23,6 & \multirow{5}{*}{0,021} \\
\hline Perokok berat & 39 & 43,8 & 0 & 0,0 & 39 & 43,8 & \\
\hline Perokok sedang & 12 & 13,5 & 13 & 14,6 & 25 & 28,1 & \\
\hline Perokok ringan & 0 & 0,0 & 4 & 4,5 & 4 & 4,5 & \\
\hline Total & 72 & 80,9 & 17 & 19,1 & 89 & 100 & \\
\hline
\end{tabular}

Menurut asumsi peneliti walaupun semua orang tahu akan bahaya yang ditimbulkan akibat merokok, perilaku merokok tidak pernah surut dan tampaknya merupakan perilaku yang masih dapat ditolerir oleh masyarakat. Hal ini dapat dirasakan dalam kehidupan sehari-hari di lingkungan rumah, kantor, angkutan umum maupun jalan-jalan.
Hampir setiap saat dapat disaksikan dandi jumpai orang yang sedang merokok. Bahkan bila orang merokok di sebelah ibuyang sedang menggendong bayi sekali pun orang tersebut tetap tenang menghembuskan asap rokoknya dan biasanya orang-orang di sekelilingnya tidak peduli. 


\begin{tabular}{c|c|c}
\hline JURNAL PENELITIAN KESMASY & VOL. 1 NO. 2 & $\begin{array}{c}\text { EDITION: NOVEMBER 2018 - } \\
\text { APRIL 2019 }\end{array}$ \\
\hline & http://ejournal.delihusada.ac.id/index.php/JPKSY & \\
\cline { 2 - 3 } & REVISED: 18 MARET 2019 & ACCEPTED: 28 APRIL 2019 \\
\hline RECEIVED: 17 FEBRUARI 2019 &
\end{tabular}

Hal ini sesuai dengan pernyataan bahwa merokok dapat memberi manifestasi atau efek merusak tuberkulosis melalui berbagai macam mekanisme. Pertama karena merokok cenderung mengakibatkan batuk kronik yang merupakan gejala utama tuberkulosis, batuk pada perokok menurunkan spesifitas dan oleh karenanya memprediksinya menjadi lebih rendah. Diagnosis tuberkulosis dapat tertunda sehingga dapat membawa ke prognosis yang lebih buruk dan dapat mengakibatkan probabilitas untuk kembali relaps lebih tinggi. Kedua, merokok tidak hanya merupakan penyebab dari penyakit-penyakit komorbid, seperti bronkitis kronis, PPOK, emfisema, dan penyakit jantung koroner, yang mana juga merupakan fasilitas untuk progresivitas dari infeksi tuberkulosis itu sendiri, akan tetapi merokok juga dapat menyebabakan kerusakan fungsi paru sehingga memperburuk penyakit tuberkulosis itu sendiri. Ketiga merokok mengakibatkan timbunan besi yang berlebihan didalam makrofag jaringan paru sebagai efek langsung dari kerusakan sel-sel respon imun untuk melawan mikroorganisme. Danyang terakhir bahwa merokok mengurangi kepatuhan terapi tuberkulosis, di suatu daerah tertentu untuk sebagian besar pasien atau dari keseluruhan pasien tuberkulosis (meskipun ini bukan masalah bagi area yang menerapkan sistem DOTS) (WHO, 2010).

Berbagai data epidemiologi telah menunjukkan bahwa merokok merupakan faktor risiko untuk terjadinya infeksi tuberkulosis paru. Kebiasaan merokok merupakan risikountuk terinfeksi Mycobacterium tuberculosis, selanjutnya infeksi akan berkembang menjadi penyakit dan berisiko kematian. Hampir $60 \%$ kematian penderita tuberkulosis berkaitan dengan kebiasaan merokok (WHO, 2010).

Penelitian ini sejalan dengan Penelitian Sarwani (2012) didapatkan hasil ada hubungan yang signifikan antara merokok dengan kejadian Tuberkulosis paru $(p=0,022$, $\mathrm{OR}=3,85 ; 95 \% \mathrm{CI}=1,32$ - 11,23). Penelitian Falletehan (2014) bahwa terdapat hubungan perilaku merokok dengan kejadian TB paru dengan nilai $p=0,027$. Begitu juga dengan Penelitian Soetioso (2014) yaitu ada hubungan antara kebiasaan merokok dengan derajat kepositivan sputum BTA $(p=0,010)$. Sejalan juga dengan penelitian Priyadi yaitu adanya hubungan yang bermakna antara kebiasaan merokok dengan kejadian TB paru.

Hal tersebut juga terlihat pada penelitian serupa yang dilakukan oleh Gupta et al bahwa merokok meningkatkan prevalensi kejadian tuberkulosis paru (Gupta, 2010). Oleh karena hubungan merokok dengan gangguan merokok atau gangguan kesehatan/ penyakit merupakan hubungan dose response (lebih lama kebiasaan merokok dijalani, lebih banyak batang rokok yang diisap setiap harinya dan lebih dalam menghisap asap rokoknya) sehingga seseorang mempunyai resiko lebih tinggi untuk mendapatkan penyakit akibat rokok (Soewarto, 2010).

\section{KESIMPULAN}

Berdasarkan hasil uji statistik dan pembahasan tersebut diatas bahwa dapat disimpulkan bahwa hubungan kebiasaan merokok dengan kejadian tuberkulosis paru di wilayah kerja Puskesmas Patumbak Tahun 2018:

a. Mayoritas masyarakat perokok beratsebsear $43,8 \%$.

b. Mayoritas masyarakat menderita TB paru sebesar $80,9 \%$.

c. Ada hubungan kebiasaan merokok dengan kejadian tuberkulosis paru.

\section{DAFTAR PUSTAKA}

Achmadi, Umar Fahmi, 2012. Manajemen Penyakit Berbasis Wilayah. Jakarta: Penerbit Buku Kompas.

Aditama, Tjandra Y, 2010. Tuberculosis Paru Masalah dan Penanggulangannya. Jakarta: UI Press.

Falletehan, 2014. Hubungan Perilaku Merokok dengan Kejadian Tuberkulosis Paru di Balai Besar Kesehatan Paru 


\begin{tabular}{c|c|c}
\hline JURNAL PENELITIAN KESMASY & VOL. 1 NO. 2 & $\begin{array}{c}\text { EDITION: NOVEMBER 2018 - } \\
\text { APRIL 2019 }\end{array}$ \\
\hline \multirow{2}{*}{ RECEIVED: 17 FEBRUARI 2019} & http://ejournal.delihusada.ac.id/index.php/JPKSY & \\
\cline { 2 - 2 } & REVISED: 18 MARET 2019 & ACCEPTED: 28 APRIL 2019 \\
\hline
\end{tabular}

$\begin{array}{lrr}\text { Masyarakat } & \text { (BBKPM) } & \text { Surakarta. } \\ \text { Fakultas Kedokteran } & \text { Universitas } \\ \text { Muhammadiyah Surakarta. } & \end{array}$

Fatimah, S. 2010. "Faktor Kesehatan Lingkungan Rumah yang Berhubungan dengan Kejadian TB Paru di Kabupaten Cilacap". Tesis. Universitas Diponegoro Semarang. (Diakses tanggal 20 November 2017).

Helmi. 2011.Stop Merokok (Sekarang atau Tidak Sama Sekali). Yogyakarta: Gerai Imu.

Hidayat. 2010. Metode Penelitian Keperawatan dan Teknik Analisa Data. Jakarta: Salemba Medika.

Istiqomah, U. 2011. Upaya Menuju Generasi Tampa Rokok. Surakarta: Cetakan I. CV Setia Aji.

Karim, 2012.Masalah TBC di Dunia. Yogyakarta: Penerbit Nuha Medika.

Kemenkes, RI, 2014. Profil Data Kesehatan Indonesia, http/Depkes.co.id. (Diakses tanggal 29 November 2017).

Komalasari, 2011.Faktor-Faktor Penyebab Perilaku Merokok Pada Remaja. Jurnal Psikologi Universitas Gadjah Mada, 2. Yogyakarta: Universitas Gadjah Mada Press.

Mu'tadin, Z. 2012. Remaja dan Rokok. http://WwW.e-

psikologi.com/remaja.050602.htm.

(Diakses pada tanggal 10 November 2017).

Manalu, H.S.P., 2014. "Faktor-Faktor yang Mempengaruhi Kejadian TB Paru dan UpayaPenanggulangannya", Jurnal Ekologi Kesehatan Vol. 9 No. 4, Desember 2010: 1340-1346.

Misnadiarly, J., 2011. Tuberkulosis Klinis. Edisi 2. Jakarta: Widya Medika.

Mukty, H. A. 2010. Dasar - Dasar IImu Penyakit Paru. Jakarta: Airlangga University Press.

Priyadi, 2014. Hubungan Kebiasaan Merokok Dengan Kejadian Tuberkulosis Paru Di Kabupaten Banjarnegara.

Notoatmodjo, S. 2010. Metodologi Penelitian Kesehatan. Jakarta: Rhineka Cipta.
Priyadi, 2014. Hubungan Kebiasaan Merokok Dengan Kejadian Tuberkulosis Paru Di Kabupaten Banjarnegara.

Sari, 2011.Epidemiologi :Penyakit Tidak Menular. Jakarta: Rineka Cipta.

Sarwani, 2012. Merokok Dan Tuberkulosis Paru(Studi Kasus di RS Margono Soekarjo Purwokerto). Prosiding Seminar Nasional Kesehatan Jurusan Kesehatan Masyarakat FKIK UNSOED.

Soetioso, 2014. Hubungan antara Merokok dengan Kejadian Tuberkulosis Paru di RSUD Dr. Soewandhie Surabaya. Fakultas Kedokteran Universitas Katolik Widya MandalaSurabaya.

Soemirat, J. 2010. Epidemiologi Lingkungan. Yogyakarta: Universitas Gadjah Mada Press.

Sarwo, 2011.Hubungan Pergaulan Teman Sebaya terhadap Tindakan Merokok Siswa Sekolah Dasar Negeri di Kecamatan Panjang Kota Bandar Lampung'.Jurnal Psikologi. Vol.3, No 3:56-61

Setiadi, 2010.Konsep dan Penulisan Riset Keperawatan. Yogyakarta: Graha Ilmu.

Sunaryati , S. S. 2014. 14 Penyakit Paling Sering Menyerang dan Sangan Mematikan. Yogyakarta: Penerbit Flashbooks.

Sitopoe, 2012.Mengapa Ragu Tinggalkan Rokok?. Jakarta:Pustaka At-Tazkia.

Sugiyono. 2012. Metode Penelitian Pendidikan . Bandung: ALFABETA.

Tarwoto, 2010.Mengapa Ragu Tinggalkan Rokok? Jakarta: Pustaka At-Tazkia.

Wardoyo, 2012.Strategi Penghentian Perilaku Merokok. Semarang: Universitas Unika Soegijapranata Press.

Zulkifli, 2012.Kontroversi Rokok, Sumbangan Rokok, Fatwa Haram, dan Politisasi Rokok.Yogyakarta: Graha Pustaka 
